\title{
Distance Education in Social Work: An Evaluation of an Undergraduate Course on Family Violence
}

\author{
Christine Ann Walsh \\ Faculty of Social Work, University of Calgary, Canada \\ E-mail: cwalsh@ucalgary.ca \\ Myra Baynton \\ Faculty of Social Work, University of Calgary, Canada \\ E-mail: mbaynton@ucalgary.ca
}

Received: February 23, 2012

Accepted: March 5, 2012

Published: May 15, 2012

doi:10.5430/ijhe.v1n1p148

URL: http://dx.doi.org/10.5430/ijhe.v1n1p148

\begin{abstract}
Social work is a discipline that emphasizes personal contact and has traditionally been taught face-to-face. This paper examines whether online learning is appropriate for educating social workers about family violence. It describes a newly-developed online course in family violence and evaluates its effectiveness. Two surveys of the class and an analysis of discussion boards provided quantitative and qualitative data. Results suggest that online teaching was effective in meeting course objectives and learner needs. The course did provide knowledge in the area of family violence that students then applied to their practices. The online learning environment proved to be safe, inclusive, acceptable and accessible to learners.
\end{abstract}

Keywords: Social work, Online learning, Course, Family violence

\section{Introduction}

Breckenridge and James (2010) suggest that "[i]nternationally and locally, human service workers face unprecedented challenges in effectively responding to clients' trauma-related experiences" (p. 259). In Canada, family violence has gained increased attention (Public Health Agency of Canada, 2009) and social work professionals play a key role in both violence prevention and in intervening with families where violence has occurred. However, many Canadian social workers reside and deliver services in rural or remote areas; they need access to information and resources to foster continuing competence in this field. As well, both geographical setting (Burke, O'Campo \& Peak, 2006; Richmond, 2007) and culture (Korbin, 2002; Pan et al., 2006; Simpson, 2005) play a role in family violence, factors important to consider in a country as large and ethno-culturally diverse as Canada (Statistics Canada, 2008). Online education offers the opportunity to address these issues. The question we intend to address in this paper is: are online learning forums appropriate for educating social workers in family violence, in a discipline that emphasizes personal contact, and which has traditionally been delivered face-to-face? In this article, we provide a review of the literature on the use of e-learning in social work as a means of framing the evaluation of a newly-developed online course in family violence. We outline the course design, objectives, content and mode of delivery. The focus of the evaluation of the course is its ability to meet course objectives and social work principles in an online format. We conclude by summarizing our learnings which may be useful for other educators interested in providing similar content through online delivery.

\section{Background}

As early as 1993, Linda Hasarim asserted that we were transforming the burgeoning technology of cyberspace into an effective and ubiquitous social network. However, some have argued that issues of an emotional nature are best handled face-to-face, based on an assumption of the importance of non-verbal cues, the need for emotional support and the availability of immediate intervention, should learners have difficulty dealing with the psychological impact of the content (Jones, 2005; Krueger \& Stretch, 2000; Moore, 2005/2008). Others have shown that a lack of face-to-face interaction does not affect learning levels. For example, Banks and Faul (2007) found that students who had a reduced number of face-to-face hours in a social work research class reported a knowledge gain equal to that of those in traditional classroom 
settings. Maidment (2006) proposed that in the "post modern world of virtual reality, it [the online environment] can also be seen to parallel workplace reflective practices, in providing debriefing, peer support and review for students who would otherwise be isolated" (p. 51). Blended learning, combining both online and traditional approaches within a course or in a complement of courses, has the potential to enhance both the effectiveness and efficiency of meaningful learning experiences (Dziuban, Hartman, \& Moskal, 2004; Garrison \& Kanuka, 2004). Banks and Faul (2007) have suggested that:

[i]n order to meet the needs of twenty-first century social work students, social work educators will need to take the challenge of breaking through the philosophical barriers of social work education by incorporating technology with traditional social work teaching methodologies (p. 781).

In the context of increasing comfort with and convenience of electronic social networking, online educational models are an obvious and valuable option to address the issue of inclusion. In times of rapid social and economic change, many people find that, for personal and professional reasons, they need to continue their education throughout their lives (Frydenberg, 2002) and because of already demanding schedules and geographical distances they may be unable to attend classes on campus. Online delivery systems are able to reach more potential students, increasing inclusion and access (Buchanan, Wilson \& Gopal, 2008; Ives \& Aitken, 2008; Madoc-Jones \& Parrott, 2005). Because students in online courses tend to come from many different geographical locations and socio-political contexts, they can use both course content and discussions to examine how social issues and policies may differ from place to place (Huntington \& Sudbery, 2005).

However, while social relationships can be formed in the virtual classroom, Cooner (2004) suggests that students may feel isolated if they miss out on the "friendships, support and camaraderie they can develop when they meet other students on a daily basis" (p. 739). Madoc-Jones and Parrott (2005) attribute this feeling of isolation to the fact that a large amount of our information-gathering and processing is based on physical appearances and non-verbal cues not available in online learning. Jones (2005) states that in the classroom, discussions on controversial topics such as gender and racism "are often buoyed by the body language of the students because body language speaks volumes about personal thoughts. When students are able to see the speaker, it bolsters the debates and enhances the learning experience for the discussion participants" (p. 93). Jones also argues that the lack of body language in online debates could possibly increase the intensity of these conversations, because students cannot see the uncomfortable body language of other students.

Anonymity may also contribute to an increased intensity in online communication, in that physical attributes and mannerisms (referred to as 'triggers of difference') which are evident in the classroom setting can often create assumptions, biases and general discomfort that hinders learning (Merryfield, 2003). Chen and colleagues (1999) have argued that one of the foundations of student-centered learning environments is cultural inclusivity. Online learning tends to be "more sensitive to the needs of cross-cultural understanding — not just making oneself understood but taking the extra step of guarding against misunderstandings" (Hudson, 2002, p. 60).

E-learning also provides increased time to form deeper-level responses in discussion threads (Buchanan, Wilson, \& Gopal, 2008; Cooner \& Hickman, 2008), more resources (for example, web-links) and enhanced opportunity for equity in participation (Merryfield, 2003). Discussion boards also give social workers the means necessary to debate and deconstruct experiences in their practicum placements and to be critical, reflective, and to connect practice with theory -- a link that is crucial in social work (Madoc-Jones \& Parrott, 2005). Asynchronous collaborative learning online has been found to increase professional competences typically acquired only through small face-to-face educational settings (Solimeno, Mebane, Tomai \& Francescato, 2008).

In a recent review of use of technology in social work education Coleman and Collins (2008) conclude that evaluative research in this field is "underdeveloped and neither well designed nor comprehensive" and that claims of effectiveness are premature (p. 1). This study adds to the growing body of literature on the effectiveness of the use of technology in social work education.

\section{Method}

\subsection{Course Design}

The authors were awarded a, University of Calgary Student Union Grant for Innovation in Teaching and Course Design, to develop the online course. Figure 1 illustrates the conceptual framework underlying the design of the course. This model highlights the interconnectedness of the learner, the content of the course and the online learning environment. Attributes of the learner include: age, gender, ethnicity, isolation or distance, values and attitudes along with personal and professional experiences. The course covered five major forms of violence including theories, prevalence and incidence, prevention and intervention with attention to social context and cultural diversity for vulnerable populations. Online, problem-based learning, synchronous \& asynchronous communication, audio-graphic system, culturally sensitive, 
emotionally supportive and safe comprised the characteristics of the learning environment. During the course students bring experiences and content they access outside the learning environment.

When developing the course, the facilitator considered who the learners might be, what experiences they might bring to the learning environment, the impact the communication process might have on their learning and their ability to master the content of the course. Similarly, the instructor needed to be cognizant of how best to deliver content that can potentially be upsetting and emotionally charged when she was not able to read the non-verbal signs of learner confusion or distress.

The undergraduate, elective course, Violence and Victimology across the Lifespan, was offered to social work students at the Faculty of Social Work, University of Calgary as part of the BSW degree requirements. The degree prepares students for generalist practice. Over the six weeks that the course was offered, it examined multiple types of family violence, with an emphasis on vulnerable or marginalized populations (for example, Aboriginal, immigrant and refugee groups, gay/lesbian/bisexual/transgendered/queer individuals, racialized minorities, homeless or individuals living in poverty, or persons with physical, emotional, or cognitive limitations) over a six-week time frame. Activities were grounded in inquiry-based learning, a constructivist method that is student-centered, and takes a questioning approach to promote understanding. This method expands skills, makes direct application to professional practice and encourages learners to reflect on their ethics, beliefs and values as social workers (Altshuler \& Bosch, 2003; Friedman et al., 2010).

\section{$<$ Insert Figure 1 $>$}

The course had four major objectives: (1) to provide knowledge in the area of family violence that fulfilled the learning needs of social workers and other professionals, and that they would apply to their practice; (2) to create a space where students felt safe to engage in a free discussion of diversity, since a main goal of social work education is "cultural competence" (National Association of Social Workers, 2001); (3) to be inclusive of students from all regions, with diverse backgrounds and social positions; and (4) to provide an online learning environment that was acceptable and accessible to such students. The success of the course was evaluated by its ability to meet these objectives.

\subsection{Course Description}

The course consisted of five distinct modules, each of which lasted approximately two weeks and was devoted to a type of violence: bullying, child maltreatment, dating violence, violence against women, and elder abuse. Learning was problem-based, with one case study in each module. Students reviewed a PowerPoint presentation that outlined the theoretical and empirical foundations relevant to the module. The presentation concluded with instructor-generated questions regarding the case, for example "Which theoretical model offers the best explanation for the violence as exhibited in this case?" Students then watched a video presenting the case -- ABC News: Bullying Story 9.08 min. $\mathrm{http}: / / \mathrm{www} . y o u t u b e . c o m /$ watch? $\mathrm{v}=6 \mathrm{Wcx} 2 \mathrm{qM} 5 \mathrm{C} 4 \mathrm{~g}$, for example, all of which were accessible online. Using the software Blackboard, students participated in an online discussion answering the questions outlined in the presentation.

Additionally, students were required to read their choice of one of six journal articles required for that module, and to participate in the specific discussion board dedicated to that article. Generally, a small group of students (4 to 6) would discuss any one paper. For each paper, one student developed questions to guide the discussion; each student was responsible for developing one or two questions about one of the readings and facilitating the discussion which also used Blackboard software.

The third component of work in each module was a small group ( 3 to 4 students) presentation in seminar format. These were focused on a specific type of violence among special populations, for example 'intimate partner violence among lesbians' or 'maltreatment of children with developmental disabilities'. The entire class participated in a real time 'virtual classroom' for these seminars, using the Elluminate-Live audio-graphic system. The system allowed students to interact using voice and typed communication as well as icons to give feedback (thumbs up, thumbs down) or call attention (raise hand). The final assignment of the course was a research paper on a self-chosen topic designed to demonstrate the integration of knowledge (theoretical and empirical) with personal and professional experience.

The instructor played a key role in facilitating communications and creating an atmosphere of egalitarianism, openness and dialogue. The paradigm of transformative pedagogy guided her activities. Transformative learning is the process through which students experience intellectual and personal growth by examining assumptions, reflecting on diverse perspectives, and ultimately acquire new knowledge and skills. Meyers (2008) suggests ways for teachers to use this approach effectively online: "(a) create a safe and inviting environment, (b) encourage students to think about their experiences, beliefs and biases (c) use teaching strategies that promote student engagement and participation, (d) pose real-world problems that address social inequalities, and (e) help students implement action-oriented solutions" (p. 220). The instructor concluded each conversation thread with a positively worded, non-judgmental summary of the positions and arguments that each participant contributed. She worked at 'being present' online to answer questions promptly and to 
monitor the tone and content of the discussions. She attempted to use a questioning approach to stimulate critical thinking skills and to encourage the application of content to personal and practice contexts.

\subsection{Course Evaluation}

The evaluation received approval from the Conjoint Faculties Research Ethics Board, University of Calgary. Two methods were used to evaluate whether the course objectives were met: a survey of students, and a content analysis of the various discussion boards. Students from the class completed an evaluation at the mid- and end-points of the course; this was administered online by the second author, who was neither a course instructor nor had any responsibility for student evaluation. Once the course had been completed and after grades had been assigned, students provided written consent for the authors to access the content of the discussion board for analysis. No data from a comparison face-to-face class was collected. The surveys were designed, constructed and imbedded in the course management system (Blackboard). The mid-term survey consisted of Likert-type scaled items regarding course content, participation, access to information, group work, and the learning environment (see Table 1). As well, several open-ended questions addressed issues such as students' perceptions of the quality of the discussions, change in practice, effectiveness of learning activities and recommendations for course improvement (see Table 2), which are presented in the discussion section.

The final feedback survey was similar (see Table 3). One Likert-type scale addressed the amount of learning, the other asked for student opinions of the quality of instruction. Open-ended questions addressed issues such as the student's most significant learning, changes in ideas about violence, actions as a result of the course, effectiveness of resources, organization of the course, impact of the online environment on learning; how the discussion boards, video and audio-graphic systems affected their learning, instructor strengths, strengths of the course, suggestions for improvement, and whether or not students would recommend the course to others. Data were aggregated for anonymity.

Discussion board postings were then reviewed, using content analysis, and major themes were identified. Analysis of the discussion board dialogues gave insight into the efficacy of providing this content using online technology and explored the nature of the learning culture. Findings from both surveys and the analysis of the discussion boards are integrated below; with direct quotations used to illustrate findings.

\section{Results}

\subsection{Participants}

Eighteen students took the course, 17 of whom were female, reflecting the larger demographic of social work students in general. Although the majority were social workers, other disciplines such as were represented such as child and youth workers and domestic violence workers. Learners came from many different cultural backgrounds, and covered a range of ages and worked in urban, rural and remote contexts. Students provided a variety of experiences, perspectives and individual learning needs related to the topic of violence.

Thirteen students completed the mid-point survey and six the final evaluation form and nine gave permission to have their discussion boards analyzed.

\subsection{Learning Needs and Application to Practice}

The majority of students (84\%) said that the content of the course was relevant to their learning needs. Their learning had an impact on the way they practiced: "this study will definitely change the way I work and counsel." When asked to identify two things they would change in their practice as a result of taking this course, students provided a variety of examples that included becoming more aware of the prevalence of and issues surrounding violence, working more in-depth with clients, making more use of available research and resources, and being more aware of the signs of violence.

Analysis of the discussion boards further supported the application of content to professional practice. Students suggested that after taking the course they would be: "more aware of unseen issues surrounding violence"; "more willing to work in facility working with violence...feel more prepared"; "take advantage of expertise of my peers on a multidisciplinary level" and; "seek info[rmation] from both scholarly sources and pop culture to understand experience of clients and what intervention is most appropriate." One learner summarized the connection between academic knowledge and professional practice, "this is something else I would look further into my practice. I think it is really important for professionals to have research in these areas".

Many students related situations from their own professional experience and made linkages from theory to practice at both the individual and societal level. These data show an application of concepts similar to that one would expect to see in a face-to-face context. 
Responses regarding "content most significant in learning" included information about the prevalence of violence in society, the incidence of Post Traumatic Stress Disorder as a result of violence, risk and protective factors for violence and types of interventions appropriate for individuals and families involved in violent relationships or situations.

\subsection{Safe Environment}

Students described the learning environment as safe, yet challenging. As one student illustrated, "thoughts and opinions were discussed but individuals were challenged to provide evidence...I felt safe expressing opinions [in an] environment of tolerance for new ideas". Students expressed appreciation for the safe environment of the course: "thanks for letting me express my views". Some students attributed their feelings of safety, specifically to the context of the online environment, as one student articulated, "[I] felt safe and critical at the same time..... [it was not] not face-to-face...thus were able to speak more openly".

Students felt safe enough to freely share personal and professional experiences (self-disclosure). Examples included: "I have a ...year old... who has been the victim of verbal sexual abuse..."; "I would just like to mention my own experiences with this...."; "I can very much relate to that, as I have experienced ..."; and "This scares me a bit into reevaluating how ready I am at working with this population".

\subsection{Inclusive Environment}

An indication that the environment was inclusive was the focus in debate and discourse on the cultural aspects of violence and learners from diverse cultural backgrounds were able to share their thinking and perceptions. Student comments reflected these concepts: "I am an immigrant who...."; "intergenerational trauma has been and continues to be a crisis for indigenous peoples in [name of her small rural town]; "Abuse definitions mainly come from Western points of view"; "I also wonder too about how our culture defines power and control"; "Unfortunately elder abuse is not [solely] a Western phenomenon" and; "Culture certainly plays a huge role in the way elders are dealt with". One student offered that she would now "be mindful of my own assumptions and biases based on my gender, my family history [and] socio-economic position".

\subsection{Acceptable and Accessible Technology}

The majority of students (77\%) stated that they felt part of a learning community. Some (23\%) expressed having difficulty in working in the small group format online. However, analysis of the discussion board postings over the course of the program showed the evolution of a sense of collegiality and co-operation. Examples of heightened mutual support include: "I can see why now why you chose the other theories so thank you for that"; "I liked the completeness of your response"; "...you made some good points that I never really thought about"; "I liked how you took this case and viewed it from many different perspectives. You helped me realize every case is unique and complex and many situations are not always what they seem"; "I'm so glad you brought up the harm reduction model...."; "Just wanted to add that I enjoyed reading the interaction you two were having." I really thought your answer was insightful" and "thanks for letting me express my views".

Most students (75\%) strongly agreed or agreed with the statement, Strategies to deal with various types of violence can be learned just as easily on line as in a regular face-to face classroom; the remainder neither agreed nor disagreed with the statement. Most also responded that they were able to find their way around the online environment and were able to access needed information and discussion boards. Some expressed frustration with the technology initially, particularly the synchronous audio-graphic system. As one student identified, "[the online environment] was frustrating and disappointing and negatively impacted my learning and involvement....". Another concurred stating that there were "difficulties ... it will make me think twice about this format". And one expressed some uncertainty in interactions: "without body language it was hard to tell if someone was joking or being harsh".

The majority of students (77\%) however, noted benefits for E-learning. Students identified flexibility and pacing as important advantages. One student commented, "it allowed me to take a course I would normally have not been able to". Another mentioned, "the online meeting gave me an opportunity to have the time to reflect on the topics of discussion" and another learner suggested that it, "[w] as nice to be able to review the discussion boards and other resources several times to be able to learn the material at my own pace".

Students found the E-learning format offered opportunities for reflection and deep learning. As one participant commented, "I found the Blackboard an effective learning tool when challenging questions were posed". Another suggested that the online nature "gave way to richer discussions that came from actual experience".

There was evidence of increasing peer-to-peer communication as the course progressed as well as a sharing of resources and information with each other. As one student noted, "the online nature allowed more experienced students to contribute 
to the group's learning experience". Another suggested, "it was nice to learn from peers". As an example, one student posed a question on Blackboard seeking a student with specific practice experience, "I was wondering if you have some recent personal experience with Child Welfare." One student concluded that education through online learning "is the only way for me."

\section{Discussion}

According to Gitterman (2004), educators "must provide the conditions which facilitate opportunities for students to bridge personal experiences and styles with facts, concepts and theories" (p. 97). Triangulated sources of data including student feedback from the surveys and data from discussion boards indicated that education about family violence can be delivered effectively in an online format. In this mode of delivery the content, learner and technology can work together to create an inclusive environment in which students met their learning needs and felt they were free to discuss issues related to violence in a safe, interactive forum. Despite some of the challenges in the online learning related to the need for training and familiarity in the use of technology, findings suggest that respondents were able to connect theory to practice and apply these learnings to their professional practice during the course. They further suggest the relevance of their newly acquired knowledge and enhanced practice skills to their future professional career.

One of the primary goals for social work education, whether in face-to-face or online environments, is to increase students' knowledge-base in preparation for effective professional practice. In order to do so the educational environment needs to be safe and supportive such that students are encouraged to reflect upon their own values and beliefs about issues. Additionally issues related to interpersonal violence, such as those discussed in this course, have direct relevancy to much of social work practice in the field. Most importantly, students need to be able to apply theoretical frameworks and empirical knowledge to their professional interventions. Findings from this evaluation suggest that the online environment was effective in facilitating students' acquisition of knowledge related to forms of family violence across the lifespan, it provided a supportive, safe environment in which self-reflection about these issues could occur and it also was useful in promoting the transfer of these skills into a variety of practice settings. Finally, acquiring skills and confidence in E-learning technology could assist in ongoing professional development through participation in continuing education courses, many of which are delivered in the online format.

\subsection{Lessons Learned}

Lessons learned from instructor experience and learner feedback include the following. A technology's ease of use can have an impact on the quality of learning. To reduce student frustration and interference with communication, training prior to the actual delivery of content is recommended. This would then allow a focus on course content rather than trying to teach content and use of technology at the same time. This training needs to include both the synchronous and asynchronous elements and should provide time for students to become familiar with the technology prior to assignments and actual content-based discussions. Students suggested: "trial Elluminate beforehand"; "have a pre-session before any commitment to take course is made to ensure it works on our system so don't lose class time"; "provide tutorials for putting up videos [into Elluminate]; "have smaller groups on Elluminate at different times rather than one large group".

Strategies to encourage the development of a learning community were also identified by students. One learner suggested that "participants post an introduction about themselves...prior to classes commencing." Another advised to include a "synchronous chat or audio-graphic element at the beginning of the course so students are introduced to the content and each other in real time". 'Face-to-face' introductions which contain personal and professional information add a personal element early on, and can provide a forum for questions, personal stories and establishing guidelines for ongoing communication were also recommended. Students noted the importance of high quality engagement. As one articulated, "I looked forward to the [Elluminate] sessions as they were an opportunity to talk to real people rather than communicate via text messages. Another offered, "I still believe the human factor should be maintained, even if only verbally over the internet".

If the emotional aspects of the content have an impact on a student's participation, ease of communication or comfort level in the class, an instructor has several options. Creating a 'safe space' in a separate discussion board or through e-mail or telephone conversation can remove the emotional or personal discussion from the regular content-based discussion and create a forum to deal exclusively with a student's need to share, express, or work through, with peers, a difficult or personal issue. Here, the emphasis is on dialogue rather than discussion or debate. It allows for the free exploration of complex, emotionally charged issues by listening deeply to another's perspective without judgment and by setting aside one's own views and assumptions. Secondly, the instructor should be available to a learner offline. Should a concern arise with a student, the instructor can contact that student via email or telephone to deal with any emotional reactions to the course content. For example, a student in the course had a history of childhood exposure to violence which she disclosed to the instructors; she was involved in professional counseling but was worried how the course content might impact on her 
learning during the course and recovery. The student and instructors engaged in telephone and online conversations for the duration of the course to monitor how the student was doing and to offer suggestions about how best to complete the course objectives.

This study is limited to the evaluation of single delivery of the course. Findings however suggest that the subject of violence and victimology can be taught effectively online. Such a format provides accessibility to professionals in rural and remote areas of the country, a forum for the discussion of cultural issues related to violence and enables the application of theory and research to the professional lives of social workers and other human service professionals.

\section{References}

Astleitner, H., \& Leutner, D. (2000). Designing instructional technology from an emotional perspective. Journal of Research on Computing in Education, 32(4), 497-510.

Banks, A. C. \& Faul, A.C. (2007). Reduction of face-to-face contact hours in foundation research courses: Impact on students' knowledge gained and course satisfaction. Social Work Education, 26(8), 780-793. http://dx.doi.org/10.1080/0261547060114050

Breckenridge, J. \& James, K. (2010). Educating social work students in multifaceted interventions for trauma. Social Work Education, 29(3), 259-275. http://dx.doi.org/10.1080/02615470601140500

Buchanan, J., Wilson, S.T., \& Gopal, N. (2008). A cross-cultural learning environment for students to explore the issue of racism: A case study involving the UK, USA and SA. Social Work Education, 27(6), 671-682. http://dx.doi.org/10.1080/02615470802201804

Burke, J. G., O'Campo, P., \& Peak, G. L. (2006). Neighborhood influences and intimate partner violence: does geographic setting matter? Journal of Urban Health, 83(2), 182-194. http://dx.doi.org/10.1007/s11524-006-9031-z PMid:16736368 PMCid:2527159

Chen, A., Mashadi, A.,Ang, D., \& Harkrider, N. (1999). Cultural issues in the design of technology enhanced learning systems. British Journal of Educational Technology, 30(3), 231-245. http://dx.doi.org/10.1111/1467-8535.00111

Coleman, H. \& Collins, D. (2008). Technology in social work education: Are we practicing what we preach? Currents: New Scholarship in the Human Services, 7(2), 1-17.

Cooner, T. S. (2004). Preparing for ICT enhanced practice opportunities in 2010: A speculative view. Social Work Education, 23(6), 731-744.http://dx.doi.org/10.1080/0261547042000294509

Cooner, T.S., \& Hickman, G. (2008). Child protection teaching: Student experiences of a blended learning design. Social Work Education, 27(6), 647- 657. http://dx.doi.org/10.1080/02615470802201721

Dziuban, C. Hartman, J. \& Moskal, P. (2004). Blended learning. Educause Connect, 7. Retrieved from: http://net.educause.edu/ir/library/pdf/ERB0407.pdf

Friedman, D.B., Crews, T.B., Caicedo, J.M., Besley, J.C., Weinberg, J, Freeman, M. (2010). An exploration into inquiry-based learning by a multidisciplinary group of higher education faculty. Higher Education, 59(6), 765-783. http://dx.doi.org/10.1007/s10734-009-9279-9

Frydenberg, J. (2002). Quality standards in E-Learning: A matrix of analysis. International Review of Research in Open and Distance Learning, 3(2), 1-15.

Garrison, R. D. \& Kanuka, H. (2004). Blended learning: Uncovering its transformative potential in higher education. The Internet and Higher Education, 7(2), 95-105.http://dx.doi.org/10.1016/j.iheduc.2004.02.001

Gitterman, A. (2004). Interactive andragogy: Principles, methods, and skills. Journal of Teaching in Social Work, 24(3/4), 95-112. http://dx.doi.org/10.1300/J067v24n03_07

Hasarim, L. M. (1993). Global Networks. Cambridge, MA: MIT Press.

Hudson, B. (2002). Critical dialogue online: Persona, covenants and candlepower. In K. Rudestam \& J. Schoenholtz-Read (Eds.), Handbook of online learning: Innovations in higher education and corporate training (pp. 77-84). San Francisco: Sage Publishers.

Huntington, A., \& Sudbery, J. (2005). Virtual classrooms: Experiences of European collaborative teaching and learning. Social Work Education, 24(3), 363-371. http://dx.doi.org/10.1080/02615470500050677

Ives, N. G., \& Aitken, O. (2008). Technology and access: Responding to the social work education needs of First Nations and Inuit communities. Social Work Education, 27(6), 683-692. ttp://dx.doi.org/10.1080/02615470802201846 
Jones, L. (2005). Maintaining the curricular philosophies of a multicutural education course: From face-to-face to elearning environments. AACE Journal, 13(1), 91- 99. http://dx.doi.org/10.1108/17504970710832817

Korbin, J. E. (2002). Culture and child maltreatment: Cultural competence and beyond. Child Abuse \& Neglect, 26(6-7), 637-644. http://dx.doi.org/10.1016/S0145-2134(02)00338-1

Krueger, L. \& Stretch, J. (2000). How hypermodern technology in social work education bites back. Journal of Social Work Education, 36(1), 103-115.

Madoc-Jones, I. \& Parrott, L. (2005). Virtual social work education- theory and experience. Social Work Education, 24(7), 755-768. http://dx.doi.org/10.1080/02615470500238678

Maidment, J. (2006). Using online delivery to support students during practicum placements. Australian Social Work, 59(1), 47-55. http://dx.doi.org/10.1080/03124070500449770

Merryfield, M. (2003). Like a veil: Cross-cultural experiential learning online. Contemporary Issues in Technology and Teacher Education, 3(2), 146-171.

Meyers, S. A. (2008). Using Transformative Pedagogy when Teaching Online. College Teaching, 56(4), $219-224$. http://dx.doi.org/10.3200/CTCH.56.4.219-224

Moore, B. (2008). Using technology to promote communities of practice (CoP) in social work education. Social Work Education, 27(6), 592-600.http://dx.doi.org/10.1080/02615470802201580

Moore, B. (2005). Key issues in web-based education in the human services: A review of the literature. Journal of Technology in the Human Services, 23(1/2), 11-28. http://dx.doi.org/10.1300/J017v23n01_02

National Association of Social Workers (2001). NASW standards for cultural competence in social work practice. Washington, DC: NASW Press.

Pan, A., Daley, S., Rivera, L. M., Williams, K., Lingle, D., \& Reznik, V. (2006). Understanding the role of culture in domestic violence: The Ahimsa Project for Safe Families. Journal of Immigrant and Minority Health, 8(1), 35-45. http://dx.doi.org/10.1007/s10903-006-6340-y PMid:19834998

Public Health Agency of Canada. (2009). The Family Violence Initiative. Retrieved from: http://198.103.98.171/ncfv-cnivf/initiative-eng.php.

Richmond, C. A. (2007). Narratives of social support and health in Aboriginal communities. Canadian Journal of Public Health, 98(4), 347-351. PMid:17896750

Simpson, A. R. (2005). Cultural issues and elder mistreatment. Clinics in Geriatric Medicine, $21(2), 355-364$. http://dx.doi.org/10.1016/j.cger.2004.11.003 PMid:15804555

Solimeno, A., Mebane, M., Tomai, M., \& Francescato, D. (2008). The influence of students and teachers characteristics on the efficacy of face-to-face and computer supported collaborative learning. Computers \& Education, 51(1), 109-128. http://dx.doi.org/10.1016/j.compedu.2007.04.003

Statistics Canada. (2008) Canada's Ethnocultural Mosaic, 2006 Census. Ottawa, ON: Minister of Industry.

Table 1. Results from Mid-point Evaluation Questions 1-7

\begin{tabular}{|c|c|c|c|}
\hline Item & $\begin{array}{l}\text { Strongly } \\
\text { Agree/ } \\
\text { Agree }\end{array}$ & $\begin{array}{l}\text { Neither } \\
\text { Agree nor } \\
\text { Disagree }\end{array}$ & $\begin{array}{l}\text { Disagree/ } \\
\text { Strongly } \\
\text { Disagree }\end{array}$ \\
\hline The course objectives were clear. & $100 \%(n=11)$ & - & - \\
\hline The content of this course is relevant/applicable to my learning needs. & $100 \%(n=11)$ & - & - \\
\hline I am able to participate at the level I expected. & $73 \%(n=8)$ & $18 \%(n=2)$ & $10 \%(n=1)$ \\
\hline $\begin{array}{l}\text { I was able to find my way around the Blackboard site, accessing the } \\
\text { information and discussions I needed. }\end{array}$ & $73 \%(n=8)$ & $18 \%(\mathrm{n}=2)$ & $10 \%(n=1)$ \\
\hline Working in a group of colleagues contributed to my learning. & $73 \%(n=8)$ & $10 \%(n=1)$ & $18 \%(n=2)$ \\
\hline I felt like I was part of a learning community in this course. & $83 \%(n=10)$ & $10 \%(\mathrm{n}=1)$ & $10 \%(n=1)$ \\
\hline $\begin{array}{l}\text { Strategies to deal with various types of violence can be learned just as } \\
\text { easily on line as in a regular face-to face classroom. }\end{array}$ & $75 \%(n=9)$ & $25 \%(n=3)$ & - \\
\hline
\end{tabular}


Table 2. Results from Mid-point Evaluation Questions 8-12

Please describe your perception of the quality of the discussions around violence in this course

-The quality of discussion surpassed my expectations. Initially, I was quite overwhelmed particularly because this is my first course on Elluminate. But, after the first two weeks everything flowed.

-It seems like everyone comes from a different background, so we all poll our knowledge.

-The quality of the discussions was great, it was nice to be able to review the discussion boards and other resources several times to be able to learn the material at my own pace.

-I have found the Blackboard discussions to be informative and thought provoking. At times however, it seems that material is merely reflected back as per the readings. I prefer the critical thinking and challenging our ways of looking at this topic.

-Quality is good one the discussions get started but there should be a requirement that the first posts must be up by Tuesday so there is time to have meaningful discussion for the rest of the week.

-I think that the quality is lacking for the ability to participate. The group presentations are very difficult to follow online,

-I found the class where each person did a little presentation added to my learning more than the Blackboard discussions.

-I think that the quality of discussions around violence would have been a bit more enriched if there was an actual textbook for this course.

-Sometimes it was hard to keep up with discussion as time on Blackboard isn't always easy.

-I am disappointed with the discussion board. I was hoping to engage in critical discussion of the topics, to hear a variety of thoughts and opinions, particularly with respect to the case studies. Instead, it seems that participants are reading the material and then recopying it word for word.

What TWO things will you change in your practice as a result of taking this course?

-Knowing risk/ protective factors for each type of violence will be very beneficial in identifying intervention strategies.

-Look for more signs of dating violence with youth I work with presently. Be more aware of issues facing elders.

-I learned a lot in this course and have noticed that I have been applying my learnings to my practicum and other courses.

-I would be more aware of the unseen issues surrounding violence. I would be more willing to work in a facility that is working with violence as I feel more prepared.

-That working relationships with victims of violence is crucial...otherwise do not know if I will change anything else in my practice as a result of this course.

-More use of research. More reflection on the interconnection of violence through the ages. I have many research ideas after taking this class $<$

-Be more in depth with clients in exploring how they have been victims of violence, for example, rather then labelling it (you were abused as a child), I would want to examine how that defines them, what coping strategies they have developed, and what we can do to overcome the abuse.

-More aware of the prevalence of violence.

-The readings were very useful as they are current and are something I can take back to my work partners in working toward the prevention of family violence and looking at best practices

What was the MOST EFFECTIVE learning activity for you in this course and WHY was it effective?

-The discussion board was most effective. Because there was not a text book, I spent time looking for and examining resources in the $\mathrm{U}$ of $\mathrm{C}$

- I liked the discussion part of this course. After reading case studies and commenting on your thoughts it was nice to learn what other aspects you left out. The saying two heads are better than one really applied in this situation. It was nice to know everyone else's perspective on certain case examples.

- The case studies. Because I learned a lot of other ways to solve/look at one problem.

-I learned the most doing the research for my group presentation but it has taken a great deal of time.

-The group project, because I have never done a group project through Elluminate before and so I was quite 
intimidated by this. I feel I learned how to do this effectively, and in sharing ideas with my group in a smaller setting I was able to engage in critical discussion, which was very beneficial to learning about my topic.

-Creating/seeing others presentations. It was nice to learn from peers.

-The class where each student did a little presentation was easier to pay attention too, and allowed me to do a little research each session.

-The research paper was effective as I was able to pick a specified area of violence and research it and in the process, build more awareness and knowledge of this particular topic.

-Most effective time-wise was completing various readings and participating in the discussions.

-The most effective learning for me was the readings and then the Blackboard discussions. I found the Blackboard an effective learning tool when challenging questions were posed and responded to.

-Reading all the required readings

- The professor was very organized which made it easier for us as students.

What was the LEAST EFFECTIVE learning activity for you in this course and WHY was it ineffective?

-The group work. It was frustrating to rely on others knowing that it impacted my mark. One person did not contribute, causing a great deal of stress. I would have preferred to do all the work on my own.

-The group project. Because Elluminate is a new environment, I feel that some people got marks docked for technological issues out side of their control, while others did not as they learned from those that went first.

-The facilitating [of the readings on the discussion board]. Only so many questions can be asked and the articles seemed like they had a few different questions that could be posed/explored from different perspectives. Chances are if you post more that one question, nobody might want to contribute to your post.

-Blackboard AND readings (one or the other would be preferable)

-The posted PowerPoint's as there is often material that needs to be discussed but cannot be. I liked the videos though. -Elluminate! This was the part of the course that was very frustrating and that negatively impacted both my learning and my sense of disconnection from my colleagues. My difficulties with Elluminate will make me think twice about this format of course delivery.

Please provide any recommendations for course improvement.

- Have a pre-session on Elluminate before any commitment is made to take the course to ensure that Elluminate works on our system and to learn how to navigate it without losing class time. Have participants post an introduction about themselves on the Blackboard prior to classes commencing.

-Elluminate should be easier to trial before hand. It seems many people so not have success with this software. There are no tutorials on how to put videos up for all to see. If they are there I couldn't see them.

-No group presentation. Other than that the instructor has been excellent, and my learning has been significant.

-No group assignments, more individual research presentations, perhaps half the class presents on the topic this week, then the next the other half and then do that repeating till the end.

Everything was great, but the only downfall is that I did not know how I was doing in the course until a lot later in the term.

-I would have liked to see clearer description of the assignments and clear expectations of the Instructor. Breaking assignments down to weekly. Listening to the recorded class when you miss a class does not seem to be relevant. A criteria for an alternative assignment could be included in the outline. A 2 page paper does not seem like enough to do justice to a topic.

The directions seemed very confusing. Maybe handing out the assignments on different days, so that the directions to complete them are clear. Maybe not having all the work (Facilitating, contribution to case studies, group presentations etc.) due in one day, but split them for the two weeks before lectures.

Instead of being marked on responses perhaps a pass/fail for contribution OR each section has 3 responses per person and a separate discussion for the whole class.

-I think all of the activities had their own benefits which enhanced the course.

-Loved the course and professor! 
Table 3. Final Evaluation

Please fill out each of the questions below. The information you provide will assist us in modifying the course to continue to meet learners' needs in the area of family violence. Additionally, the information will be used to assess the ability of this type of course to meet learners' needs.

1. Please describe your most significant learning about violence from this course?

2. Did this course change your ideas about violence in any way?

a) If yes, in what way?

3. What will you do differently as a result of taking this course?

a) With your clients?

b) With your personal relationships?

c) Other?

4. This was the first time this course was offered on line. What suggestions do you have to improve this course?

5. Please comment on the effectiveness of the resources provided

6. Please comment on how well you thought the course was organized

7. How did the online learning environment influence/impact your learning?

8. How would you describe the learning environment (open? safe? critical? challenging etc?)

a) What factors contributed to this atmosphere?

9. How would you describe the effectiveness of the instruction in this course?

10. Did the Discussion Board for the case examples contribute to your learning?

a) Please describe

11. Did the Discussion Board for the readings contribute to your learning?

a) Please describe

12. Did the YouTube videos contribute to your learning?

a) Please describe

13. Did the Elluminate sessions contribute to your learning?

a) Please describe

14. Would you recommend this course to others?

a) Why or why not?

15. Any further comments, thoughts, or ideas? 


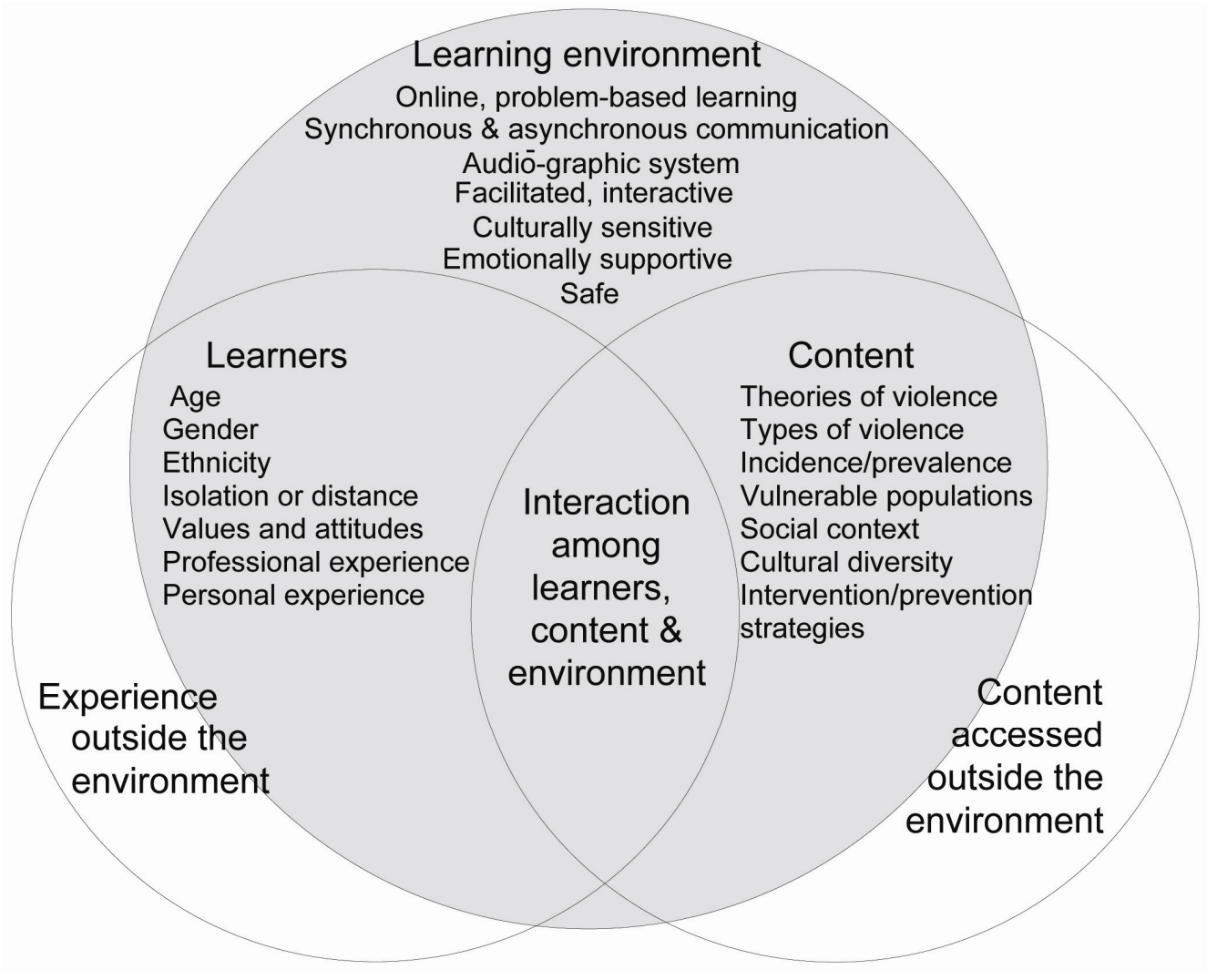

Figure 1. Violence and Victimology Across the Lifespan Course Model 